\title{
SPIRITUALITAS AGAMA DAN MASYARAKAT MODERN: Eksistensi Tarekat Qadiriyah wa Naqsyabandiyah di Bandar Lampung)
}

\author{
Suhandi \\ Universitas Islam Negeri Raden Intan Lampung \\ subandi@radenintan.ac.id
}

\section{Abstract}

As a form of increasing tendency for the spirituality of the people, Indonesia has developed a wide range of orders, among which are the Qadiriyah wa naqsyabandiyah (so that they are included in the Muktabarah order). These orders are a combination of two orders (Qadiriyah and Naqsyabandiyab) performed by Sheikh Ahmad Khatib al-Sambasi al-Jawi, The dissemination of the teachings of the Qadiriyah wa Naqsyabandiyah in the Sambas district of West Kalimantan (originally Sheikh Ahmad Khatib al-Sambasi) by his two caliphs, namely Nur al-Din Shaykh of the Philippines and Shaykh Mubammad Sa'ad the original son of Sambas. In Bandar Lampung in particular TQN was held and developed in the Way Halim Bandar Lampung at the Al-Hikmah Boarding Board Foundation led by KH. Mubammad Shobari's father. After doing research using qualitative and quantitative approach (mixed methodes design). research begins with data collection activities and ends with data analysis. In data collection activities are used Quesioner Observation, Interview, documentation and dissemination methods. Once all the required data has been collected, it is analyzed using mixed methodes design. It was further concluded that the pattern of spiritual upliftment was made by the Qadiriyah wan Naqsyabandiyah (TQN) orders led by KH. Muhammad Sobari as chair of the Al-Hikmah Way Halim Bandar Lampung Boarding Foundation is emphasizing on the aspects of fasting and fasting that is practiced on a daily and weekly and monthly basis. In addition, the moral aspect of alkarimah is also a concern that is always taught by KH. Muhammad Sobari, 
both through the teachings of al-hasanah (in the form of lectures and advice) and through the example of trustworthiness exemplified in everyday life. So the Qadiriyah wan Naqsyabandiyah (TQN) rules are very influential to the spiritual growth of the pilgrims.

\section{Abstrak}

Sebagai bentuk kecenderungan meningkatnya spiritualitas masyarakat, di Indonesia berkembang berbagai aliran tarekat, di antaranya yang sangat termasybur adalah tarekat Qadiriyah wa naqsyabandiyah (sehingga tarekat ini termasuk ke dalam tarekat Muktabarah). Tarekat ini merupakan penggabungan dua tarekat (Qadiriyah dan Naqsyabandiyah) yang dilakukan oleh Syeikh Ahmad Khatib al-Sambasi al-Jawi,Penyebaran ajaran tarekat Qadiriyah wa Naqsyabandiyah di daerah Sambas Kalimantan Barat (asal Syeikh Ahmad Khatib al-Sambasi) dilakukan oleh dua orang khalifahnya, yaitu syaikh Nur al-Din dari Filipina dan Syaikh Muhammad Sa'ad putra asli Sambas.Di Bandar Lampung khususnya TQN dijalani dan dikembangkan di daerah Way Halim Bandar Lampung pada Yayasan Pondok Pesantren Al-Hikmah yang dipimpin oleb bapak KH.Muhammad Shobari. Setelah dilakukan penelitian dengan menggunakan pendekatan kualitatif dan kuantitatif (mixed methodes design). research diawali dengan kegiatan pengumpulan data dan akhiri dengan analisa data. Pada kegiatan pengumpulan data digunakan metode Observasi, Wawancara, dokumentasi, dan penyebaran Quesioner. Setelab semua data yang dibutubkan terkumpul, dianalisa dengan menggunakan analisa kulitatif dan kuantitatif (mixed methodes design). Selanjutnya disimpulkan babwa Pola pengembangan peningkatan spiritual yang dilakukan oleh tarekat Tarekat Qadiriyah wan Naqsyabandiyah (TQN) yang dipimpin oleh KH. Muhammad Sobari sebagai pimpinan Yayasan Pondok Pesantren Al-Hikmah Way Halim Bandar Lampung adalah dengan penekanan pada aspek drikir dan puasa yang dilakukan secara rutin pada tiap hari dan minggu serta bulanannya. Selain itu juga aspek akblak al-karimah juga menjadi perhatian yang selalu diajarkan oleb KH. Muhammad Sobari, baik melalui mavidzah al-hasanah (dalam bentuk ceramah-ceramah dan nasihat-nasihat) dan dengan cara uswatun hasanah yang dicontohkan dalam kehidupan sehari-hari. Sehingga tarekat Qadiriyah wan Naqsyabandiyah (TQN) Sangat berpengarub terhadap peningkatan spiritual para jama'ah tarekat. 
Keywords: Spirituality, Modern Society, Qadiriyah wa Naqsyabandiyah

\section{A. Pendahuluan}

Sufisme dan tarekat ${ }^{1}$ merupakan wacana dan praktek keagamaan yang cukup populer di Indonesia. Bahkan akhir-akhir ini kecenderungan sufistik telah menjangkau kehidupan masyarakat kelas menengah sampai masyarakat kelas atas (elite) dengan angka pertumbuhan yang cukup signifikan terutama di daerah perkotaan. Tampaknya gejala gaya hidup ala sufistik mulai digandrungi sebagian orang yang selama ini dianggap bertentangan dengan kondisi dan gaya hidup mereka (perkotaan). Gejala ini bisa jadi sebagai bentuk pemenuhan unsur spiritual yang belum juga terpenuhi oleh ibadah rutin.

Di Indonesia berkembang berbagai aliran tarekat, di antaranya yang sangat termasyhur adalah tarekat Qadiriyah wa naqsyabandiyah. Tarekat ini merupakan penggabungan dua tarekat (Qadiriyah dan Naqsyabandiyab) yang dilakukan oleh Syeikh Ahmad Khatib al-Sambasi al-Jawi, ${ }^{2}$ Penyebaran ajaran tarekat Qadiriyah wa Naqsyabandiyabjuga berkembang di daerah Lampung yang dibawa oleh oleh Syaikh Haji Ahmad Lampung. ${ }^{3}$

Di Bandar Lampung khususnya TQN dijalani dan dikembangkan di daerah Way Halim Bandar Lampung pada Yayasan

${ }^{1}$ Dalam wacana tasawuf, istilah tarekat ini sampai abad ke $11 \mathrm{M} / 5 \mathrm{H}$. Dipakai denga pengertian jalan yang lurus yang dipakai oleh setiap calon sufi untuk mencapai tuuannya, yaitu berada sedekat mungkin dengan Allah SWT atau dengan kata lain berada di hadirat-Nya tanpa dibatasi oleh dinding atau hijab. Edangkan ikhtiar untuk menempuh jalan itu dinamakan suluk. Dan orang yang bersuluk disebut salik. Jadi tarekat itu berarti kebiasaan atau trdisi (sunnat), sejarah kehidupan suatu kehidupan jama'at. Sedangkan menurut Martin Van Bruiness bahwa tareqat sebagai suatu intuisi belum ada sebelum abad ke $8 \mathrm{H} / 14 \mathrm{M}$ berarti bahwa tareqat merupakan sebuah ajaran baru yang tidak ada dalam ajaran Islam yang asli. Namun demikian, bila dilihat secara mendalam ternyata ajaran-ajaran pokoknya memiliki keterkaitan akar yang kuat sampai kepada Rasulullah. Lihat Martin Van Bruiness, Tareqat Naqsabandiyah di Indonesia, Mizan, Bandung 1992, h. 15.

2Ras'an Rusli, Tasawnf dan Tarekat Studi Pemikiran dan Pengalaman Sufi, PT. Raja Grafindo Persada, Jakarta, 2013, h. 215.

${ }^{3}$ Martin Van Bruinessen, Tarekat Naqsyabandiyah di Indonesia, Mizan, Bandung, 1994, h. 92. 
Pondok Pesantren Al-Hikmah yang dipimpin oleh bapak KH. Muhammad Shobari. Sebagai tokoh agama dan tokoh masyarakat KH. Ahmad Shobari mengembangkan ajaran TQN yang sudah dimulai pada tahun 1982. Tarekat Qadiriyah wa Naqsybandiyah ini memiliki silsilah berasal dari Syaikh KH. Muhammad Sholeh yang berasal dari Mojosari Mejokerto Jawa Timur, beliau berguru dengan Syaikh KH. Musthofa Kedung Sumur Mejokerto. Guru KH. Musthofa adalah Syaikh KH. Ahmad Dasuki Krian Mejokerto. Selanjutnya silsilah mursyid KH. Ahmad Dasuki adalah Syaikh KH. Abdul Karim al-Bantani yang berupakan murid dari Syaikh KH. Ahmad Khatib al-Sambasi sebagai pendiri Tarikat Qadiriyah wa Naqsyabandiyah. ${ }^{4}$

Menguatnya gejala sufistik yang terjadi pada semua lapisan masyarakat, mengindikasikan bahwa nilai-nilai yang terkandung dalam ajaran tarekat secara psikologis mampu membawa anak bangsa ini menuju masyarakat yang lebih bermartabat dan manusiawai, sehingga tarekat diharapkan dapat mengatasi sebagian persoalan hidup terutama dalam bidang moralitas dan pengembangan potensi masyarakat dengan pendekatan spiritual. Oleh karena itu, dalam penelitian ini akan melihat lebih jauh bagaimana doktrin dan ajaran serta perkembangan tarekat Qadiriyah wa Naqsyabandiyahdi Bandar Lampung pada Yayasan Pondok Pesantren Al-Hikmah yang dipimpin olehbapak KH. Muhammad Shobari dan bangaimana kontribusinya terhadap pembinaan spiritualitas masyarakat Islam di Bandar Lampung.

Untuk menjawab permasalah pokok dalam tema ini maka dirumuskan dua permasalahan sebagai berikut:

1. Bagaimanakah pola pengembangan spiritual tarekat Qadiriyah wa Naqsyabandiyah di Bandar Lampung?

2. Bagaimanakah kontribusi tarekat Qadiriyah wa Naqsabandiyah terhadap pengembangan spiritual masyarakat Islam di Bandar Lampung?

\section{B. Pembahasan}

${ }^{4}$ Wawancara dengan KH. Ahmad Shobari, Pembina Yayasan Al-Hikmah dan pengembang TQN, pada tanggal 17 Maret 2016. 


\section{a. Memahami Tarekat \\ 1. Pengertian Tasawuf}

Tarekat secara etimologi berasal dari bahasa Arab, yaitu thariqat yang memiliki arti jalan, keadaan, dan aliran dalam garis sesuatu. ${ }^{5}$ Atau dapat juga berarti jalan yang terang, dan lurus yang memungkinkan sampai pada tujuan dengan selamat. ${ }^{6}$ Sedangkan secara terminologi tarekat adalah jalan atau petunjuk dalam melakukan sesuatu ibadah sesuai dengan ajaran yang dicontohkan oleh Nabi Muhammad dan dikerjakan oleh sahabat-sahabatnya, tabi'in dan tabi'it tabi'in turun-menurun sampai kepada guru-guru secara berantai sampai pada masa kita ini. ${ }^{7}$ Selain itu, tarekat juga difahami di kalangan sufiyah atau para kaum sufi sebagai sutau sistem dalam rangka mengadakan latihan jiwa, membersihkan diri dari sifatsifat yang tercela dan mengisinya dengan sifat-sifat yang terpuji dan memperbanyak zikir dengan penuh ikhlas semata-mata untuk mengharapkan bertemu dengan dan bersatu secara ruhiah dengan Tuhan. ${ }^{8}$ Jalan dalam tarikat itu antara lain terus-menerus berada dalam zikir atau ingat terus kepada Tuhan, dan terus-menerus menghindarkan diri dari sesuatu yang melupakan Tuhan.

Dari penjelasan di atas, maka dapat diambil pemahaman bahwa tarekat adalah jalan yang bersifat spiritual yang di dalamnya berisi amalan ibadah berupa dzikir, dan amalan-amalan lainnya yang diorientasikan untuk menyebut nama Allah swt dan sifat-sifatnya dengan penghayatan yang sepenuh hati dan mendalam. Dan semua amalan yang dilakukan dalam kegiatan tarekat ditujukan untuk memperoleh hubungan sedekat mungkin (secara rohaniah) dengan Allah swt.

\section{Tujuan Tasawuf}

Tarekat sebagai kegiatan para sufi yang telah melembaga dan sudah terorganisir dengan baik sudah barang tentu memiliki tujuan yang telah terencana dengan baik pula. Dalam Kamus Ilmu Tasawuf,

${ }^{5}$ Louis Ma'luf, Munjid fi al-Lughah wa al-A'lam., (Beirut: daar al-Masyriq, 1986)., h.465.

${ }^{6}$ Jamil Shaliba, Al-Mu'jam al-Falsafi, Juz II, (Beirut: Dar al-Kitab, 1979), 1995), cet.I, h.56.

${ }^{8}$ Ibid., h.57. 
tujuan tasawuf adalah mempelajari kesalahan-kesalahanpribadi, baik dalam melakukan amal ibadah atau dalam mempergauli manusia dalam masyarakat dan memperbaikinya. Pekerjaan ini dilakukan oleh para mursyid yang pengetahuan dan pengalamannya jauh lebih baik, dari pada murid yang akan diasuhnya dan dibawa kepada perbaikanperbaikan yang dapat menyempurnakan keislamannya dan memberikan dia kebahagiaan dalam menempuh jalan kepada Allah swt. Oleh karenanya kesalahan murid itu tidak sama maka perbaikanperbaikan yang diciptakan oleh ahli tarekat itupun bermacam-macam bentuknya.

\section{Awal Munculnya Tarekat}

Ditinjau dari segi historinya, kapan dan tarekat mana yang mula-mula timbul sebagai suatu lembaga, sulit diketahui dengan pasti. Namun, Dr. Kamil Musthafa Asy-Syibi dalam tesisnya tentang gerakan tasawuf dan gerakan Syi'ah mengungkapkan, tokoh pertama yang memperkenalkan sistem thariqah (tarekat) itu Syekh Abdul Qadir Al-Jaelani (w. 561 H/1166 M) di Baghdad, Sayyid Ahmad Ar-Rifa'i di Mesir dan dengan Tarekat Rifa'iyyah, dan Jalal Ad-Din Ar-Rumi (w. $627 \mathrm{H} / 1273 \mathrm{M})$ di Parsi. ${ }^{10}$ Sementara menurut Abdul al-Mu'thi, sejarah ribath yang paling tua adalah yang didirikan oleh Abdullah bin Zaid (w.177 H/793 M) di sebuah pulau Abadan di Teluk Persia. Kemudian disusul oleh rihath-rihath yang terdapat di Bizantium, Afrika Utara, Damaskus, Palestina dan lain sebagainya. ${ }^{11}$

Pada awalnya tarekat merupakan suatu kegiatan spiritual sufi secara individu. Kemunculannya ditandai dengan adanya zabid-zabid yang mengasingkan diri dan mengembara dari satu tempat lain. Kemudian terbentuklah tempat-tempat pendidikan sebagai pusat kegiatan sufi. Tempat ini dinamakan dengan ribath atau zawiyah. ${ }^{12}$ Mulanya zawiyah ini hanya digunakan sebagai tempat peristirahatan para zahid, kemudian berkembang menjadi semacam

9 Totok Jumantoro \& Samsul Munir, Kamus Imu Tasawuf, (Wonosobo, AMZAH: 2012), h. 244.

10 M. Solohin \& Rosihan Anwar, Ilmu Tasawuf, (Bandung: CV. Putaka Setia, 2008). h. 207

11 Abdul al-Mu'thi, Tarekat: Sejarah Timbulnya, Macam-macamnya dan Ajaranajarannya, (Jakarta: Paramadina, t.t.), h. 141-142.

${ }^{12}$ Ris'an Rusli, Tasawuf dan tarekat: Studi Pemikiran dan Pengalaman Sufi, (Jakarta: PT. Rajagrafindo Persada, 2013), h. 189. 
asrama yang di dalamnya terdapat seorang syaikh bersama muridmuridnya.Sayaikh tersebut bertugas mengawasi ajaran-ajaran atau praktik sufinya, sehingga ajaran-ajaran tasawufnya itu bias terobsesi.Ribath itu didirikan oleh Mamluk, yang muncul pada masa dinasti Saljuk. Mereka mengadakan kegiatan dan latihan kerohanian secara bersama. ${ }^{13}$

Di akhir abad ke-5 $\mathrm{H}$ terjadi perubahan besar di kalangan fuqaha yang sebelumnya membenci tasawuf berbalik menerimanya sebagai bagian dari ajaran Islam.Akibat dari penerimaan ini timbulah kebutuhan terhadap organisasi yang dapat menyalurkan hasrat kehidupan rohani mereka.Kemudian organisasi tersebut berubah menjadi suatu aliran yang berdiri sendiri yang disebut dengan tarekat. ${ }^{14}$

Peralihan tasawuf yang bersifat personal kepada tarekat yang bersifat lembaga tidak terlepas dari perkembangan dan perluasan tasawuf itu sendiri.Semakin luas pengaruh tasawuf, semakin banyak pula orang yang berhasrat mempelajarinya.Untuk itu, mereka menemui orang yang memiliki pengetahuan dan pengalaman yang luas dalam pengalaman tasawuf yang dapat menuntun mereka.Sebab, belajar dari seorang guru dengan metode mengajar yang disusun berdasarkan pengalaman dalam suatu ilmu yang bersifat praktikal merupakan suatu keharusan bagi mereka.Seorang guru tasawuf biasanya memang memformulasikan suatu sistem pengajaran tasawuf berdasarkan pengalamanya sendiri. Sistem pengajaranya itulah yang kemudian menjadi ciri khas bagi suatu tarekat yang membedakanya dari tarekat yang lain. ${ }^{15}$

Demikian halnya Jhon O. Voll menjelaskan dengan teori lain; bahwa sejarah kemunculan tarekat sebagai mistis dalam Islam muncul sejak awal sejarah Islam, dan para sufi yang mengembangkan jalanjalan spiritual personal mereka dengan melibatkan praktik-praktik ibadah, pembacaan kitab suci, dan kepustakaan tentang kesalehan. Para sufi ini kadang-kadang terlibat konflik dengan otoritas-otoritas dalam komunitas Islam dan memberikan alternatif terhadap orientasi

${ }^{13}$ Harun Nasution, op. cit., h. 59-90.

14 IAIN Syarif Hidayatullah, Ensiklopedi Islam Indonesia (Jakarta: Djambatan, 1992), h. 927.

${ }^{15}$ Ibid., h. 274. 
yang lebih bersifat legalistik, yang disampaikan oleh kebanyakan ulama. Namun, para sufi secara bertahap menjadi figur-figur penting dalam kehidupan keagamaan di kalangan penduduk awam dan mulai mengumpulkan kelompok-kelompok pengikut yang diidentifikasi dan diikat bersama oleh jalan tasawuf khusus (tarekat) sang guru. Menjelang abada ke -12 M (ke-5 H), jalan-jalan ini mulai menyediakan basis bagi kepengikutan yang lebih permanen, dan tarekat-tarekat sufi pun muncul sebagai organisasi sosial utama dalam komunitas Islam.

\section{Guru dan Murid dalam Tarekat}

Adab kepada mursyid (syeikh) merupakan ajaran yang sangat prinsip dalam tarekat, bahkan merupakan syarat dalam riadlah (latihan) seorang murid. Adab atau etika antara murid dengan mursyidnya diatur sedemikian rupa, sehingga menyerupai adab para sahabat dengan nabi Muhammad saw. Hal yang sedemikian ini karena diyakini bahwa hubungan (mu'asyarah) antara murid dan mursyid adalah melestarikan tradisi (Sunnah) yang terjadi pada masa nabi ${ }^{16}$

Dalam peningkatan fungsi guru ini berkaitan erat dengan perubahan besar dalam pengamalan ajaran tasawuf.Tasawuf yang sejak awal pertumbuhannya merupakan gerakan individual dan elitism, maka semenjak abad ke-12 $\mathrm{M}$ berubah menjadi ordo-ordo tarekat.Dalam fase ini muncul ikatan-ikatan komunal di bawah bimbingan seorang guru atau syeikh yang mengamalkan teknik-teknik dzikir tertentu dan sejumlah aurad-aurad yang ditemukan seorang guru pencipta ordo tarekatnya.Dengan perantara teknik-teknik dzikir dan aurad-aurad tersebut, maka tarekat dapat dikikuti oleh golongan awam seacra massal.Perubahan dari gerakan eltisme individual menjadi gerekan arus bawah secara massal di samping memang merupakan kodrat dari perkembangan ajaran itu sendiri, juga meruapakan tututan perkembangan masyarakat.

\section{b. Spiritualitas}

\section{Pengertian Spritualitas}

16 Annemarie Schimel, Mystisical Dimension of Islam, terjemah: S. Djoko Damono, dkk, dengan judul Dimensi Mistik Dalam Islam, (Jakarta: Pustska Firdaus, 1986), hm. 242. 
Piritual, spiritualitas, dan spiritualisme mengacu kepada kosa kataLatin spirit atau spiritus yang berarti nafas.Adapun kerja spirare yang berarti untuk bernafas.Berangkat dari pengertian etimologis ini, maka untuk hidup adalah yang bernafas, dan memiliki nafas artinya memiliki spirit. ${ }^{17}$ Spirit dapat juga diartikan kahidupan, nyawa, jiwa, dan nafas. Spiritual adalah kesadaran tentang diri dan kesadaran individu tentang asal, tujuan, dan nasib. Di mana individu memiliki hubungan yang erat dengan sang pencipta dan sesama. Spiritualitas bukan hanya keyakinan atau agama.Tetapi spiritualitas bagaimana dapat membuat kehidupan ini bisa lebih baik dan berarti dengan hubungan dengan Tuhan dan juga sesama. Spiritualitas merupakan potensi batin yang memberikan dorongan bagi manusia untuk melakukan kebijakan bagaimana menghadapi dan memuliakan orang lain di luar diri.

\section{Bentuk-Bentuk Spiritualitas}

Ada tiga bentuk spiritual yang harus dimiliki oleh seorang muslim; yakni akhlak terhadap Allah SWT, aklhlak sesama makhluk (manusia), dan juga akhlak terhadap binatang, tumbuh-tumbuhan, dan benda-benda yang tak bernyawa. ${ }^{18}$

1. Akhlak terhadap Allah

Aklhak kepada Allah SWT dapat diartikan sebagai sikap atau perbuatan yang seharusnya dilakukan oleh manusia sebagai makhluk kepada Tuhan sebagai Khlalik. Sikap atau perbuatan tersebut merupakan cerminan rasa penghambaan manusia terhadap Allah SW'T, sehingga akhlak yang diwujudkan adalah dalam bentuk ibadah, mulai dari shalat, dzikir, puasa, haji dan semua bentuk ketaatan terhadap semua yang menjadi perintah Allah SWT.

2. Akhlak terhadap sesama manusia

Akhlak sesama manusia jika ingin dirinci sedemikian rupa sangat banyak, yakni semua yang terkait dengan hubungan dan perlakukan sesame mnusia. Petunjuk mengenai hal itu bukan hanya dalam bentuk larangan melakukan hal-hal yang negatif;

17 Hasan, Aliah B. Purwakania, Psikologi Perkembangan Islam, Jakarta:PT Rajagrafindo Persada, 2006), h. 288

18 M. Quraish Shihab, Wawasan Al-Qur'an (bandung: Mizan, 1996), h. 261. 
seperti membunuh, menyakiti badan, atau mengambil harta tanpa alas an yang benar, melainkan juga sampai menyakiti hati dengan jalan menceritakan aib seseorang di belakangnya. Selain itu Islam juga mengajarkan kepada muslim untuk semua manusia ditempatkan secara wajar, tidak masuk ke dalam rumah siapa pun tanpa izin, jika bertemu mengucapkan salam, ucapan yang dikeluarkan hendaklah ucapan-ucapan yang baik dan benar, tidak mengucilkan seseorang atau atau suatu kelompok, tidak boleh berperansangka buruk, memberikan julukan atau panggilan dengan pangilan yang buruk, jika melakukan kealfaan atau kesalahan kepada orang lain wajib meminta maaf, dan jika orang lain yang melakukan kesalahan kepada kita maka kita harus memaafkan kesalahan orang lain, menjadi orang yang pemurah dan pemberi, jangan menjadi orang yang pemarah, mendahulukan kepentingan orang lain yang lebih memerlukan, dan lain sebagainya yang mengandung kebaikan dan kemaslahatan untuk orang lain.

\section{Akhlak terhadap lingkungan}

Manusia hidup tidak terlepas dari lingkungan yang mengitarinya, baik yang bergerak maupun yang tidak bergerak.Lingkungan disini adalah segala sesuatu yang selain manusia; bias binatang, tumbuh-tumbuhan atau benda-benda mati lainnya.Sebagai perwujudan dari Islam yang ramatalan lil alamin, manusia harus memiliki sikap yang mulia kepada semua makhluk yang ada di muka bimi ini. Sehingga dengan keberadaan seorang muslim semuanya akan terlindungi, dan terjaga kelestariannya.

Pada dasarnya akhlak yang diajarkan al-Qur'an terhadap lingkungan bersumber dari fungsi manusia sebagai khlaifah.Kekhalifahan menuntut adanya interaksi antara manusia dengan sesamanya dan manusia terhadap alam.Kekhalifahan mengandung arti pengayoman, pemeliharaan, serta bimbingan, agar setiap mahluk mencapai tujuan penciptaannya.Dalam Islam diajarkan agar kita tidak boleh memetik buah yang belum matang dengan tujuan yang tdak jelas, memetik bunga sebelum mekar, merusak dahan pohon, karena hal ini berarti tidak 
memberi kesempatan kepada mahluk untuk mencapai tujuan penciptaannya. ${ }^{19}$

Hal di atas menggambarkan bahwa manusia dituntut untuk mamapu menghargai proses-proses yang sedang berjalan, dan terhadap semua proses yang sedang terjadi. Hal semacam ini mengajarkan kepada manusia agar hidupnya selalu memiliki rasa tanggang jawab yang ttinggi terhadap semua kehidupan di alam semesta ini. Maka yang akan hadir adalah jiwa-jiwa dan sikapsikap mental yang tidak menjadi perusak terhadap lingkungan.

Binatang, tumbuh-tumbuhan, dan benda-benda tak bernyawa semuanya diciptakan oleh Allah SWT, dan menjadi milik-Nya, keyakinan ini akan membawa manusia terhadap teologi lingkungan, bahwa semua lingkungan ini adalah milik Allah dan kita selaku hamba-Nya pautut menjaga apa yang menjadi rencana dan ciptaan Allah SWT. Agar kehidupan kita senantiasa mendapatkan keridhaan dari-Nya.

\section{Metode Peningkatan Spiritualitas}

\section{a. Pendidikan keimanan}

Iman merupakan potensi spiritual yang dapat mendorong manusia selalu ingat untuk melaksanakan kewajibannya kepada Allah, dengan cara memperbanyak ibadah dan kewajibannya kepada sesame mahluk dengan hubungan sosial yang kontinyue. Danpotensi iman mesti ada pada setiap diri manusia; baik manusia yang dilahirkan oleh orang yang beragama maupun manusia yang dilahirkan oleh orang ateis.Potensi tersebut dinamakan fitrah. Dan fitrah merupakan ptensi bawaan manusia sejak lahir, yang menerima perkembangannya ketika mulai berinteraksi dengan lingkungannya sampai ia mencapai kematangannya. Proses tingkat kematangan sangat dipengaruhi oleh lingkungan rumah tangga, lingkungan sekolah, dan lingkungan masyarakat dimana dia berinteraksi. Selanjutnya iman juga merupakan potensi kerohanian yang mendasari seluruh tingkah laku manusia dalam menjalani kehidupannya.

19 Abuddin Nata, Akblak Tasawnf dan Karakter Mulia, Jakarta: PT. RajaGafindo Persada, 213), h. 129 
Pendidikan iman merupakan upaya menumbuh-kembangkan kondisi kepercayaan hamba untuk meyakini tentang apa yang dia percayai sebagai sesuatu yang dianggap mutlak dalam kehidupannya; dalama hal ini adalah rukun iman yang enam harus benar-benar tertanam dalam jiwanya. Pertama, bahwa Allah SWT adalah Wujud Yang Esa yang tidak didahuli oleh wujud yang lain, yang keberadaan-Nya bersifat baqa. Kedua, percaya bahwa malaikat Allah termasuk malaikat Allah termasuk hamba-Nya yang yang mulia karean tidak pernah menyalahi perintan-Nya, dan tidak pernah melebihi dan mengurangi sedikitpun.Ketiga, menumbuh-kembangkan kepercayaan bahwa kitab Allah merupakan kalam-Nya yang mengandung kebenaran mulak, yang diturunkan kepada rasul-rasul-Nya melalui malaikat Jibril.Keempat, mempercayai bahwa rasul yang diutus untuk memimpin umat dengan tuntunan kitab suci-Nya merupakan figure dan manusia pilihan yang memiliki kondisi fisik dan rohani yang sempurna, serta perilaku yang mulia.Kelima, menumbuh-kembangkan kepercayaan bahwa sesudah hidup nanti, manusia hidup lagi di alam yang lain, yang disebut dengan alam akhirat. Di sanalah kehidupan selama-lamanya, sesudah melalui proses pemeriksaan dan pembalasan dari seluruh amalan yang telah dikerjakan manusia ketika masih hidup di dunia. Dan disana ada surge tempatnya orang-orang yang beruntung (beriman dan beramal shaleh), da nada neraka tempat orangorang yang celaka.Keenam, percaya kepada qadar baik dan buruk yang telah ditentukan dan ditetapkan oleh Allah SWT bagi seluruh mahluk-Nya. ${ }^{20}$

Pendidikan berlangsung pada dir setiap manusia dengan berbagai macam bentuk; bias dilakukan dengan pendidikan informa, nonformal atau formal. Bentuk pendidikan formal dilakukan dengan cara yang terencana dan teratur, memiliki waktu tertentu, perangkat kurikulum yang telah direncanakan, serta tenaga pengajarnya ang sesuai dengan kualifikasi tingkat pendidikan tertentu. Sedangkan bentuk pendidikan informal dan nonformal, tidak dilakukan secara teratur sebagaimana halnya dengan pendidikan yang berbentuk formal.

${ }^{20}$ Mahjuddin, Akblak Tasawuf II, (Jakarta: Kalam Mulia, 2012), h. 67-68. 
b. Pendidikan ketaqwaan

Pendidikan taqwa merupakan upaya menumnbuh-kembangkan realisasi kekuatan iman menjadi perbuatan yang dilandasi amar ma'ruf dan nabi munkar. Begitu kuatnya hubungan iman dengan taqwa, maka Abdul al-Aziz al-Dairayni menganalogikan iman dan taqwa bagaikan pohon kurma yang pangkal batangnya tertanam dengan kuat di dalam tanah, sedangkan pelepah dan daunnya menjulang tinggi ke langit. Sama halnya dengan iman yang tertanam dengan kuat dalam hati, sedangkan cabangnya terlihat dalam perilaku manusia yang bersifat amal shaleh yang tidak terhitung banyaknya. ${ }^{21}$

Proses berlangsungnya pendidikan taqwa seiring dengan berlangsungnya pelaksanaan ibadah ritual dan ibadah sosial. Semakin tinggi intensitas ibadah yang dilakukan oleh manusia, semakin tinggi pula upaya-upaya untuk mendidik ketaqwaannya.Ketika taqwanya telah mendasari segala macam perbuatannya kepada Allah dan kepada sesame manusia, maka itulah yang disebut dengan aqidah al-maqamat.Tetapi ketika taqwa mendasari ma'rifah terhadap Allah, maka itulah yang disebut dengan a'la al-maqamat.Tingkatan taqwa inilah yang dimilki oleh para wali dan nabi.

c. Pendidikan sosial

Muslim yang ideal adalah orang yang tidak hanya mementingkan dirinya, tetapi juga sangat peduli terhadap lingkungannya, baik lingkungan alamnya maupun lingkungan sosialnya.Ia menyadari bahwa keberadaannya tidak terlepas dari keberadaan lingkungannya, sehngga ia berusaha untuk tidak merusak lingkungan alamnya dan tidak menolak tatanan sosial yang berlaku di masyarakatnya.

Pendidikan sosial adalah suatu upaya untuk menanamkan atau membentuk sikap yang selalu ingin memperhatikan kepentingan umum.Karena pendidikan sosial merupakan salah satu bagian dari pendidikan akhlak, maka ia adalah termasuk salah satu kegiatan untuk menumbuh-kembangkan kepribadian seoranf

${ }^{21}$ Ibid. h. 72 
muslim; yaitu orang yang patuh menjalankan agamanya dan peduli terhadap hajat orang lain dan lingkungan hidupnya.

Jadi sasaran yang ingin dicapai dalam pendidikan sosial adalah sikap dan perilaku yang tidak hanya mementingkan diri sendiri, namun memiliki kepedulian terhadap lingkungan dimana dia bersosialisasi dengan masyarakat sekitarnya, dan selalu eksis untuk dapat berbagi dengan yang lainnya.

d. Pendidikan keterampilan

Manusia dianugerahi oleh Allah SWT dunia dengan berbagai macam benda, hewan dan tumbuh-tumbuhan di dalamnya, untuk dikelola menjadi barang yang siap dimanfaatkan.Oleh karenanya, manusia harus memiliki kemampuan untuk mengelolanya, dan kemampuan itulah yang disebut dengan skill atau keterampilan.

Untuk mewujudkan hal tersebut, Islam menganjurkan dan bahkan mewajibkan agar seorang muslim selalu menuntut ilmu, atau sekurang-kurangnya belajar dari pengalaman hidunya, sehingga dapat memperoleh pengetahuan; bahwa produksi barang atau jasa yang dibutuhkkan dalan kehidupan manusia dapat dihasilkan setelah manusia bekerja dengan sungguhsungguh dan dilakukan secara maksimal, sehingga baru Allah SWT menetapkan ketentuan-Nya. Tentu saja keyakinan seperti ini hanya dapat dilakukan oleh orang-orang yang telah memiliki dasar-dasar keimanan dan ketaqwaaan yang kokoh.Perlu juga difahami bahwa terwujudnya suatu produksi menurut pandangan para ahli ekonomi modern karena adanya sumberdaya alam, modal, tenaga manusia dan tenaga organisasi (management). ${ }^{22}$ Dan khussu unuk tenaga manusia, baik yang berupa fisik maupun non-fisik atau berupa pikiran, dapat diberdayakan dengan melalui pendidikan. Dan pendidikan keterampilan merupakan salah satu bagian dari pendidikan akhlak dalam upaya menumpuhkembangkan kepribadian muslim yang berbasis spiritual.

Pendidikan akhlak sebagai salah satu tujuan yang akan diwujudkan dalam kehidupan sufistik atau gerakan tarekat haruslah selalu berada dalam setiap bidang kehidupan manusia, termasuk dalam kehidupan ekonomi, untuk menuntut manusia

${ }^{22}$ Ibrahim Lubis, Ekonomi Islam, (Jakarta, Kalam Mulia 1995), h. 303 
bekerja dengan tekun dan terampil untuk memperoleh rizki yang halal dan mengarahkan kepada upaya-upaya yang penuh dengan keridhaan Allah SWT. Pekerja yan terampil, jujur dan penuh dedikasi, meruapakn indikator pekerja muslim yang berwawasan spiritual yang mapan dan sempurna.

\section{c. Data dan Temuan Penelitian}

\section{Pola pengembangan spiritual tarekat Qadiriyah wa Naqsyabandiyah}

Yayasan Al-Hikmah yang dipimpin oleh bapak KH. Muhammad Shobari. Sebagai tokoh agama dan tokoh masyarakat KH. Muhammad Shobari mengembangkan ajaran TQN yang sudah dimulai pada tahun 1982. Tarekat Qadiriyah wa Naqsybandiyah ini memiliki silsilah berasal dari Syaikh KH. Muhammad Sholeh yang berasal dari Mojosari Mejokerto Jawa Timur, beliau berguru dengan Syaikh KH. Musthofa Kedung Sumur Mejokerto. Guru KH. Musthofa adalah Syaikh KH. Ahmad Dasuki Krian Mejokerto. Selanjutnya silsilah mursyid KH. Ahmad Dasuki adalah Syaikh KH. Abdul Karim al-Bantani yang berupakan murid dari Syaikh KH. Ahmad Khatib al-Sambasi sebagai pendiri Tarikat Qadiriyah wa Naqsyabandiyah. ${ }^{23}$

TQN yang dikembangkan oleh KH. Ahmad Shobari bersamaan dengan Yayasan Al-Hikmah yang merupakan sebuah Yayasan yang bergerak di bidang pendidikan Islam. Melalui Yayasan Al-Hikmah yang didirikan pada tahun 1976, sudah berdiri sekolah Tingkat Dasar (Madrasah Ibtidaiyah), Tingkat Menengah (Madrasah Tsanawiyah), dan Tingkat Atas (Madrasah Aliyah). Selain bergerak pada bidang pendidikan formal, pada Yayasan ini juga telah dibuka pondok pesantren Al-Hikmah yang telah menampung sejamlah santri dari berbagai daerah. TQN ini telah memiliki jama'ah dzikir sekitar 800 orang yang dilaksankan pada setiap hari Rabu malam pukul 21.00 sampai dengan selesai dan hari Kamis setelah sebelum dan sesudah shalat Ashar. ${ }^{24}$

${ }^{23}$ Wawancara dengan KH. Muhammad Sobari, Pembina Yayasan Al-Hikmah dan pengembang TQN, pada tanggal 22 Maret 2018.

${ }^{24}$ Ibid. 
Ajaran-ajaran tarekat yang senanatiasa dikemukakan oleh $\mathrm{KH}$. Muhammad Sobari ${ }^{25}$ antara lain adalah :

1. Baiat dan Dzikir

Pada tahap permulaan seorang yang akan memasuki dunia tarekat harus melakukan baiat yang tidak lain adalah umpah atau pernyataan kesetiaan yang diucapkan oleh seorang murid kepada guru mursyid sebagai symbol penyucian serta keabsahan seseorang dalam mengamalkan ilmu tarekat. Jadi baiat menjadi semacam upacara sacral yang harus dilakukan oleh setiap orang yang ingin mengamalkan tarekat.Leh karenanya, dalam upacara baita ini selain diucapkan sumpah juga diajarkan kewajiban seorang murid untuk menaati guru yang telah membaiatnya. Dengan berbaiat,maka seseorang memperoleh status keanggotaan secara formal, membangun ikatan spiritual dengan musryidnya, dan membangun persaudaraan spiritual dengan anggota yang lain.

Dalam upacara baiat juga diajarkan zikir yang harus dilakukan oleh seorang murid dalam sehari semalam. Zikir yang dilakukan oleh anggota tarekat yang baru tidak lain dimaksudkan untuk mengendalikan nafsu tercela (madremumah) dan menumbuh kembangkan nafsu terpuji (mahmudah). Ada 3 jenis zikir yang dilakukan oleh pengamal tarekat. Pertama, zikir nafi isbat, yang dilakukan dengan menguapkan "laailahaillallah ", kedua, zikir ismu zat dengan mengucapkan "Allah “. Kemudian ketiga, zikir hifz al-anfus yang dilakukan dengan mengucapkan klimat " hu allah " pelaksanaan zikir.Tarekat mematrealisasikan dirinya dalam zikir yang praktek regularnya mengantarkan sang arif yang ditadirkan menuju keadaan ketengelaman ( istighraq) dalam tuhan.

\section{Tobat.}

Tobat adalah kembali dari alam materi ke alam rohani, setelah terbutakannya cahaya fitrah dan rohani tersebut oleh gelapnya hawa nafsu karena dosa-dosa dan kedurhakaan.Ketika

${ }^{25}$ Wawancara dengan KH. Muhammad Sobari, Ketua Yayasan Al-Hikmah Bandar Lampung, tanggal: 22April 2018. 
manusia melakukan sesuatu perbuatan buruk, secara otomatis sebuah titik hitam mewarnai hatinya. Semakin ia melakukan perbuatan dosa, semakin meningkat pula jumlah dan kadar hitam dan kegelapan pada hatinya, hingga titik hitam dan kegelapan itu menyelimuti hatinya, sehingga hati benar-benar gelap gulita.

Adapun tahapan atau fase yang harus dilalui dalam melakukan pertobatan, antara lain adalah: Pertama, Meningalkan dosa dengan sekuat hati dan niat. Berarti tidak akan mengulangi kembali sama sekali perbuatan-perbuatan dosa yang pernah dilakukan. Jika terdapat kemungkinan pada suatu saat akan mengerjakan kembali, maka belum dikatakan tobat. Demikian juga jika tidak ada kepastian dalam hatinya, hatinya ragu-ragu untuk menghentikan perbuatan dosa, menghentikan dosa hanya untuk sementara, maka belum dikatakan tobat.Kedua, Meninggalkan dosa yang pernah dilakukannya.Ketiga, perbuatan dosa yang pernah dilakukannya harus setimpal atau seimbang dengan dosa yang ditinggalkannya sekarang.Keempat, meninggalkan perbuatan dosa semata-mata untuk mengagungkan Allah SWT, bukan karena yang lainnya.

\section{Sabar}

Kata sabar berasal dari bahasa Arab yang artinya adalah menahan.Kata ini dipewrgunakan untuk objek yang sifatnya material atau immaterial.Secara umum sabar difahami sebagai sikap yang tabah dalam menghadapi sesuatu yang sulit, berat dan pahit, yang harus diterima dan dihadapi dengan penuh tanggung jawab.Namun demikian sabar bukanlah sesuatu yang harus diterima seadanya, bahka sabar adalah usaha kesungguhan yang juga merupakan sifat Allah yang sangat mulia dan tinggi.Sabar ialah menahan diri dalam memikiul suatu penderitaan, baik dalam sesuatu perkara yang tidak diinginkan maupun dalam kehilangan suatu yang disenangi. Sabar juga merupakan sikap jiwa yang ditampilkan dalam penerimaan sesuatu, baik yang berkenaan dengan penerimaan tugas dalam bentuk perintah dan larangan maupun dalam bentuk perlakuan orang lain serta sikap menghadapi suatu musibah. Oleh karenanya sikap sabar harus dimiliki oleh 
orang-orang yang berupaya mendekatkan diri kepada Allah SWT.

\section{Zuhud}

Zuhud diartikan sebagai ketidak pedulian terhadap daya tarik duniawai dan hidup dengan cermat dan dengan memilih untuk menghindarkan diri dari semua dosa, memandang rendah dunia dalam aspek material dan nafsunya. Dalam pandangan yang lain, bahwa zuhud difahami dinginnya dunia ini adalah bahwa hati seseorang tidak terpengaruh pada dunia bagaimanapun nilainya dan cahaya gemerlapnya. Keadaan ini disebabkan hatinya sangat percaya pada Allah dengan kasih sayang-Nya yang diiringi dengan karunia-Nya yang melimpahlimpah. Dengan kepercayaan demikian maka hatinya selalu tenteram dan selamat dari was-was setan dan hawa nafsu. Sehingga pada perasaan dan pandagan hatinya. meninggalkan sesuatu dan berpaling darinya, tanpa kecenderungan dan keinginan kepadanya, juga memiliki makna bahwa meremehkan dan merendahkannya. Singkatnya zuhud difahami sebagai meninggalkan segala kesenngan fana duniawi demi kebahagiaan abadi ukhrawi.

5. Tawakkal

Tawakkal adalah kepercayaan dan penyerahan diri kepada taqdir Allah dengan sepenuh jiwa dan raga. Dalam kajian tasawuf tawakkal diartikan sebagai suatu keadaan jiwa yang tetap berada selamanya dalam ketenangan dan ketenteraman, baik dalam keadaan suka maupun duka, dirinya akan bersabar serta tidak resah dan gelisah. Penyerahan diri kepada Allah SWT artinya menyerahkan segala urusan pada taqdir Yang Maha Kuasa, yaitu selepas seorang yang bertawakkal menjalani maqomat: tuabah, sabar, dan zuhud. Seseorang yang menyerahkan diri sepenuhnya kepada Tuhan meyakini kekuasaan dan kekatan-Nya shingga ia tidak cemas dan gelisah terhadap akibat apa pun yang menimpa dirinya. Tawakkal bukanlah bermakna seseorang itu akan bersikap pasif dan bersemangat melarikan diri dari pribadi yang benarbenar memahami hidup serta menerima kenyataan hidup dengan tepat pula. 


\section{Mahabbah}

Mahabbah dalam maqam ini yang dimaksud adalah cintanya seorang hamba kepada Allah SWT, yakni suatu upaya yang kuat dari hambanya untuk mewujudkan rasa cinta dan kasih sayang yang ditujukan kepada Allah SWT.Juga dapat dimaknai sebagai luapan hati dan gejolaknya ketika dirundung keinginan untuk bertemu dengan Kekasih, yaitu Allah SWT.Dalam tarekat menjadikan mahabbah sebagai tempat persinggahan orang yang berlomba-lomba untuk memperoleh cinta Ilahi menjadi sasaran orang-orang yang beramal dan menjadi curahan orang-orang yang mencintai Tuhannya.

\section{Ridha}

Ridha merupakan puncak dari maqam-maqam keutamaan.Ia merupakan inti dari akhlak mulia. Kalau diibaratkan dengan emas, maka ridhaabagaikan emas 24 karat yang sudah ditempa dengan bara api yang sangat panas. Bila manusia telah sampai ke tingkat ridha, berarti dia telah sampai ke tingkat tertinggi dari maqam-maqam sikap hidup. Bila orang telah sampai ke tingkat tertinggi dari suatu tempat, niscaya akan tampaklah olehnya segenap alam yang di bawahnya, tampaklah kebiruan laut, tampaklah hijaunya daratan bumi dengan sunga-sungainya yang melingkar mengaliri daratan rendah, kelihatan atap-atap rumah di dusun-dusun dan di kota-kota mengkilap disinari mentari.

\section{Peningkatan Spiritual Jama'ah}

Ada beberapa aspek yang mengalami peningkatan secara spiritual terhadap jama'ah tarekat Qadiriyah wan Naqsyabandiyah (TQN) yang yang dikembangkan oleh KH. Muhammad Sobari, di antaranya :

1. Shalat

Sebagian besar jama'ah adanya peningkatan spiritual untuk memiliki perhatian terhadap shalat, yakni sebagian besar mereka selalu menjaga waktu atau kedisiplinan dalam melaksanakan ibadah shalat.melaksanakan shalat selalu dilakukan secara berjama'ah, hal ini menunjukkan mereka 
memiliki spiritualitas yang tinggi untuk mendapatkan pahala dan derajat, serta ketaatan di sisi Allah SWT.Dan mereka merasa shalatnya lebih khusu' setelah mengikuti tarekat.

2. Puasa

Puasa Ramadhan adalah kewajiban yang harus ditunaikan sebagai seorang muslim, dan merupakan salah satu dari rukun Islam. Dan 100\% jama'ah tarekat menunaikan ibadah tersebut. Hal ini menunjukkan bahwa secara spiritual ketaatan meraka terhadap kewajiban yang harus dijalankan sebagai seorang muslim telah menjadi prioritas. jama'ah telah melaksanakan puasa sunnah hari senin dan kamis yang biasa dilakukan rasulullah saw.melaksanakan puasa-puasa selain yang diajarkan dalam tarekat, yakni puasa-puasa sunnah yang dianjurkan oleh nabi saw.ada peningkatan puasa yang dilakukannya sebelum mereka mengikuti tarekat.hampir semua pengamal tarekat mengalami ketikmatan di saat menjalankan puasa.

3. Dzikir

Hampir seluruh jama'ah tarekat selalu menjalani dzikir yang diajarkan pleh guru tarekat.Dan tentu saja secara spiritual dzikir sangat berguna dalam menentramkan hati dan menenangkan pikiran, sehingga dalam menjalani kehidupan lebih nikmat, karena dijalni penuh dengan sasana yang nyaman dan tentram.Di kalangan pengamal tarekat, dzikir merupakan metode spiritual dalam pendekatan diri kepada Allah SWT dalam hati atau menghadirkan Allah dalam hati, sehingga keberadaan Allah itu disadari benar-benar oleh orang yang berdzikir dan akan mempengaruhi segala perbuatannya. Karena dirasakan dzikir dapat menentramkan hati dan merasakan dekat dengan Allah SWT.

4. Kejiwaan

Ketenteraman sangat dibutuhkan dalam menjalani kehidupan.Dan ketentraman besifat batini, sehingga tidak dapat diukur dengan menggunakan alat atau media tertentu. Untuk mengetahui tingkat ketentraman hidup seseorang dapat dilihat dari beberapa indikator cara mensikapi 
kehidupan ini. Para pengamal tarekat merasa kehidupannya lebih tenteram dijalani setelah mengikuti kegiatan tarekat, hal ini terlihat dari tabel di atas, dimana jama'ah TQN memilih jawaban dengan hidup lebih tenteram sebanyak 78 orang atau $97,5 \%$.

\section{Kehidupan Sosial}

Menjadi orang yang lebih baik dan lebih berguna adalah bagian dari tujuan dari kehidupan bertasawuf, karena dalam kehidupan tasawuf manusia harus memiliki akhlak yang baik sesama manusia.Hal ini menuntut para pengikut tasawuf untuk dapat bersosialisasi dengan masyarakat, agar dirinya lebih banyak bermanfaat untuk orang banyak.Memiliki jiwa sosial yang tinggi dan senang membantu kepada masyarakat, menunjukkan bahwa sebagain besar jama'ah tarekat suka memberikan bantuan kepada masyarakat, hal ini merupakan kesadaran spiritual, karena agama kita mengajarkan dan menganjurkan untuk membantu kepada siapa saja yang membutuhkan bantuan. Karena siapa yang suka membantu Allah pun akan membatunya.

\section{Penutup}

Tarekat Qadiriyah wan Naqsyabandiyah (TQN) yang yang dikembangkan oleh KH.Muhammad Sobari sebagai pimpinan Yayasan Pondok Pesantren Al-Hikmah Way Halim Bandar Lampung.Sangat berpengaruh terhadap peningkatan spiritual para jama'ah tarekat.Hal ini terlihat dari sebagian besar jama'ah sebagai responden peneliian sekitar $85 \%$ memberikan jawaban yang sangat signifikan terhadap peningkatan spiritual dalam kehidupan yang mereka jalani.

Aspek-aspek yang mengalami peninggkatan secara spiritual antara lain: Bidang Pengembangan Individu: Shalat, Puasa, dzikir, dan kejiwaan. Pada bidang ini peningkatannya sangat signifikan rata-rata mencapai sampai $84 \%$.Sedangkan Bidang kehidupan sosial: Kehidupan keluarga, bertetangga dan bermasyarakat hanya mengalami peningkatan pada responden sekitar $75 \%$. 


\section{Daftar Pustaka}

Abdul al-Mu'thi, Tarekat: Sejarah Timbulnya, Macam-macamnya dan Ajaran-ajarannya, (Jakarta: Paramadina, t.t.).

Abuddin Nata, Akblak Tasawnf dan Karakter Mulia, Jakarta: PT. RajaGafindo Persada, 213).

Annemarie Schimel, Mystisical Dimension of Islam, terjemah: S. Djoko Damono, dkk, dengan judul Dimensi Mistik Dalam Islam, (Jakarta: Pustska Firdaus, 1986).

Hasan, Aliah B. Purwakania, Psikologi Perkembangan Islam, (Jakarta:PT Rajagrafindo Persada, 2006).

IAIN Syarif Hidayatullah, Ensiklopedi Islam Indonesia Jakarta: Djambatan, 1992).

Ibrahim Lubis, Ekonomi Islam, (Jakarta, Kalam Mulia 1995)

Jamil Shaliba, Al-Mu'jam al-Falsafi, Juz II, (Beirut: Dar al-Kitab, 1979).

Louis Ma'luf, Munjid fi al-Lughah wa al-A'lam., (Beirut: daar al-Masyriq, 1986).

M. Quraish Shihab, Wawasan Al-Qur'an (bandung: Mizan, 1996).

M. Solohin \& Rosihan Anwar, Ilmu Tasawnf, (Bandung: CV. Putaka Setia, 2008).

Mahjuddin, Akblak Tasawuf II, (Jakarta: Kalam Mulia, 2012).

Martin Van Bruiness, Tareqat Naqsabandiyah di Indonesia, Mizan, Bandung 1992.

Martin Van Bruinessen, Tarekat Naqsyabandiyah di Indonesia, Mizan, Bandung, 1994.

Mustafa Zahri, Kunci Memahami Ilmu Tasawnf. (Surabaya: Bina Ilmu, 1995), cet.I.

Ras'an Rusli, Tasawuf dan Tarekat Studi Pemikiran dan Pengalaman Sufi, PT. Raja Grafindo Persada, Jakarta, 2013.

Ris'an Rusli, Tasawuf dan tarekat: Studi Pemikiran dan Pengalaman Sufi, (Jakarta: PT. Rajagrafindo Persada, 2013). 
Spiritualitas Agama dan Masyarakat Modern

Totok Jumantoro \& Samsul Munir, Kamus Ilmu Tasawnf, (Wonosobo, AMZAH: 2012). 
Suhandi 